\title{
Influence of land surface aridification on regional monsoon precipitation in East Asian summer monsoon transition zone
}

\author{
Yulong Ren ${ }^{1}$ (D) Ping Yue ${ }^{1} \cdot$ Qiang Zhang ${ }^{1} \cdot$ Xiaoyun Liu $^{1}$ \\ Received: 12 May 2020 / Accepted: 4 January 2021 / Published online: 21 January 2021 \\ (C) The Author(s) 2021
}

\begin{abstract}
The East Asia summer monsoon transition zone, a unique area of transition from humid monsoon to arid continental climate, has the most prominent aridification in the world, and has experienced land surface aridification (LSA) in recent years. To investigate the influence of LSA on regional monsoon precipitation, two numerical experiments were run for vegetation degradation over a long period (30 years). Then, precipitation variation of different magnitudes was analyzed. After that, the mechanism of LSA influence on precipitation was studied. The results show that aridification reduced average summer precipitation by $5 \%$. Additionally, LSA considerably changed the frequency of precipitation. Unlike aridification in North Africa caused by albedo variation, LSA in our study area mainly reduced surface thermal capacity, increased surface temperature, sharply increased the transport of surface sensible heat, and raised the atmospheric convective boundary layer. This reduces atmospheric moist static energy, which is not conducive to the generation of precipitation. LSA also increases the surface landscape gradient, local horizontal gradient of land surface turbulent flux, and probability of heavy convective precipitation. This paper reveals the mechanism by which land surface anomalies affect precipitation, which lays a foundation for follow-up studies.
\end{abstract}

\section{Introduction}

As a response to global warming, global aridification has become an indisputable fact (IPCC 2013; Mitchell et al. 2016; Dai 2012; Zhang et al. 2015; Ou et al. 2013; Cheng and Huang 2016). This aridification is even more pronounced in semiarid regions, which account for $15 \%$ of the global land area and are home to $\sim 14 \%$ of the global population. As a unique component of the land, semiarid regions, with their large rainfall variability, fragile ecological environments, and strong sensitivity to climate change and human activity (Donat et al. 2017; Li and Wang 2018; Tiwari et al. 2017; Orlowsky and Seneviratne 2012; Zhang et al. 2017c) have become a frequent topic of studies on global climate change.

Located in the East Asian summer monsoon transition zone, the semiarid region in China is a farming-pastoral ecotone and climate-sensitive and ecologically fragile zone

Yulong Ren

Yulong.Ren.renyl@iamcma.cn

Institute of Arid Meteorology, CMA, Key Laboratory of Arid Climatic Change and Reducing Disaster of Gansu Province, Key Laboratory of Arid Climate Change and Disaster Reduction of CMA, Lanzhou 730020, China
(Huang et al. 2015), where extreme climate events are frequent and climate change is strongly affected by interannual changes at the northern edge of the summer monsoon (Tang et al. 2006). In the context of global warming, aridification in this region has accelerated (Feng and Fu 2013; Huang et al. 2012; Ma et al. 2018; Zhao et al. 2014). Overall, the arid and semiarid regions in Northwest China have become increasingly arid over the past century (Zhang et al. 2017a). Summer precipitation in the semiarid regions of North China has decreased considerably, and the trend of aridification has become increasingly apparent, which is similar to the trend in the Sahara region of Africa (Ma and Ren 2007). Moreover, boundaries of the semiarid regions are expanding notably eastward and southward (Ma and Fu 2005).

Studies on how vegetation change affects regional climate change show that LSA dries out the soil, degrades vegetation, intensifies desertification, and substantially changes land surface characteristic parameters. This influences energy transfer between the land surface and atmosphere, thereby modifying the regional climate (Cao et al. 2015; Ding et al. 2018; Hua and Chen 2013; Li et al. 2014; Wei 2016; Li et al. 2013; Zhao et al. 2018;). First to propose the influence of landatmosphere interaction on aridification in the 1970s, Otterman attributed the long-term aridification in the Sahel to exposed surfaces caused by excessive grazing (Huang 


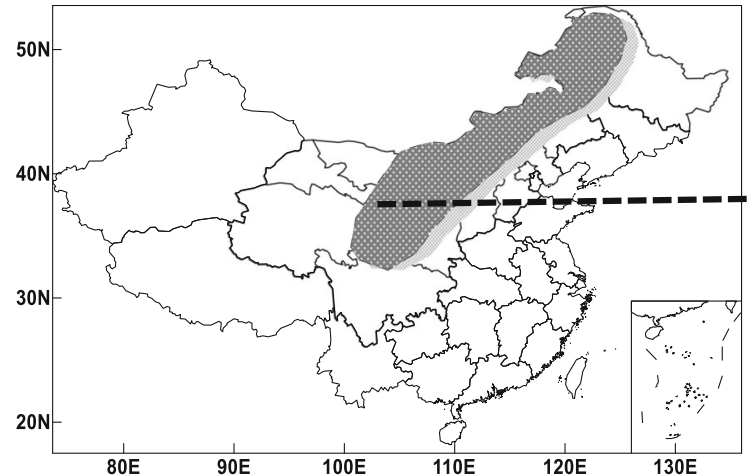

Fig. 1 Location of study area and type and distribution of land use. (Cook et al. 2014) Crop/mixed farmland, (Chen and Sun 2015) short grass, (Cao et al. 2015) evergreen coniferous tree, (Cheng and Huang 2016) deciduous coniferous tree, (Chen et al. 2017) deciduous broadleaf tree, (Dickinson et al. 1986) evergreen broadleaf tree, (Dickinson et al. 1989) tall grass, (Dickinson et al. 1993) desert, (Dai 2012) frozen soil, (Donat

et al. 2015; Otterman 1974). Based on observational data, Gou et al. (2018) found that vegetation restoration has a cooling effect on regional climate by increasing surface evapotranspiration, and weakens the influence of temperature increase on ecosystems of the Loess Plateau. According to a simulation by Zhao and Liu (2015),
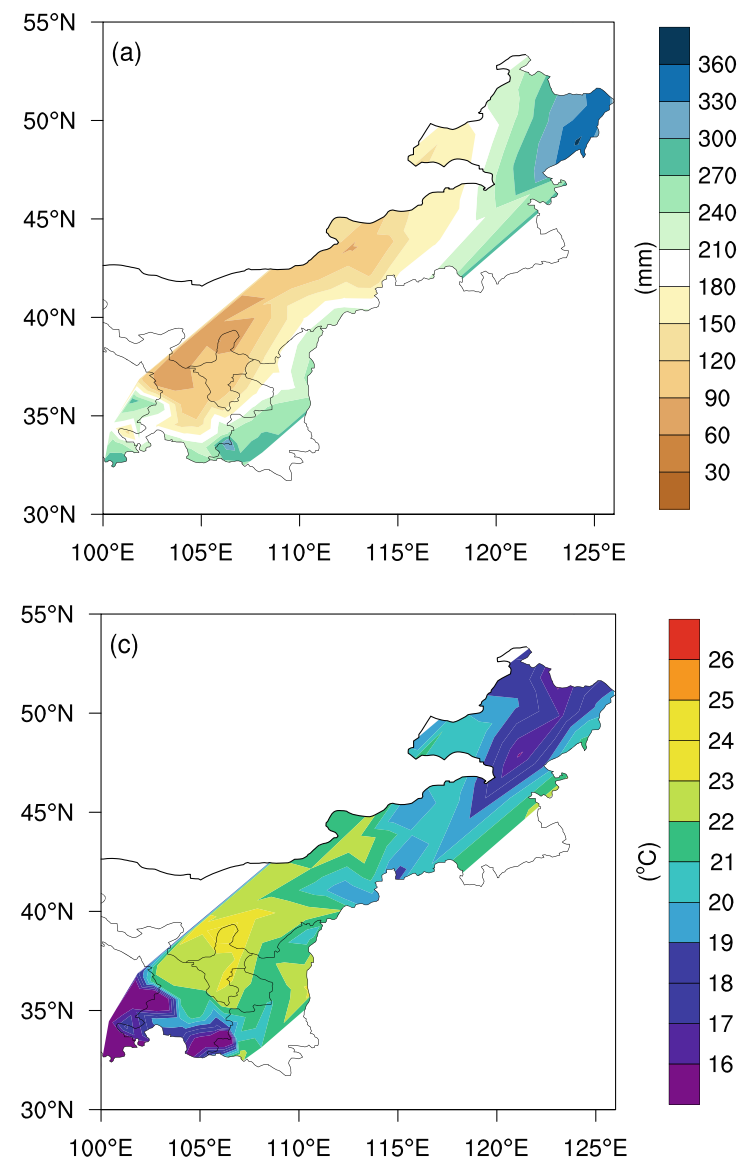

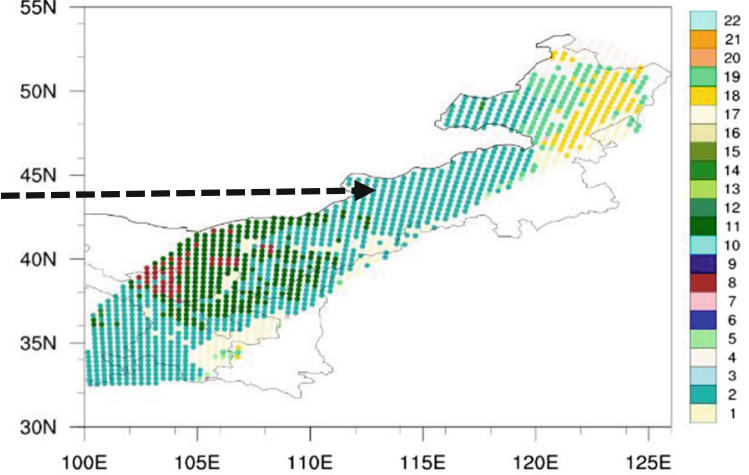

et al. 2017) irrigated crop, (Ding et al. 2018) semi-desert, (Fu et al. 2005) ice caps/glaciers, (Feng and Fu 2013) swamp, (Giorgi and Bates 1989) inland water, (Giorgi et al. 1993a) oceans, (Giorgi et al. 1993b) evergreen shrub, (Gou et al. 2018) deciduous shrubs, (Huang et al. 2012) mixed woodland, (Hua and Chen 2013) forest/field mosaics, (Huang et al. 2015) wetlands, (IPCC 2013) city, (Li et al. 2013) suburbs

vegetation has a strong influence on surface hydrological processes in Northwest China, because vegetation can accelerate the surface hydrologic cycle and reduce changes in land surface evapotranspiration. The authors also found that vegetation change substantially affects the climate in adjacent areas.
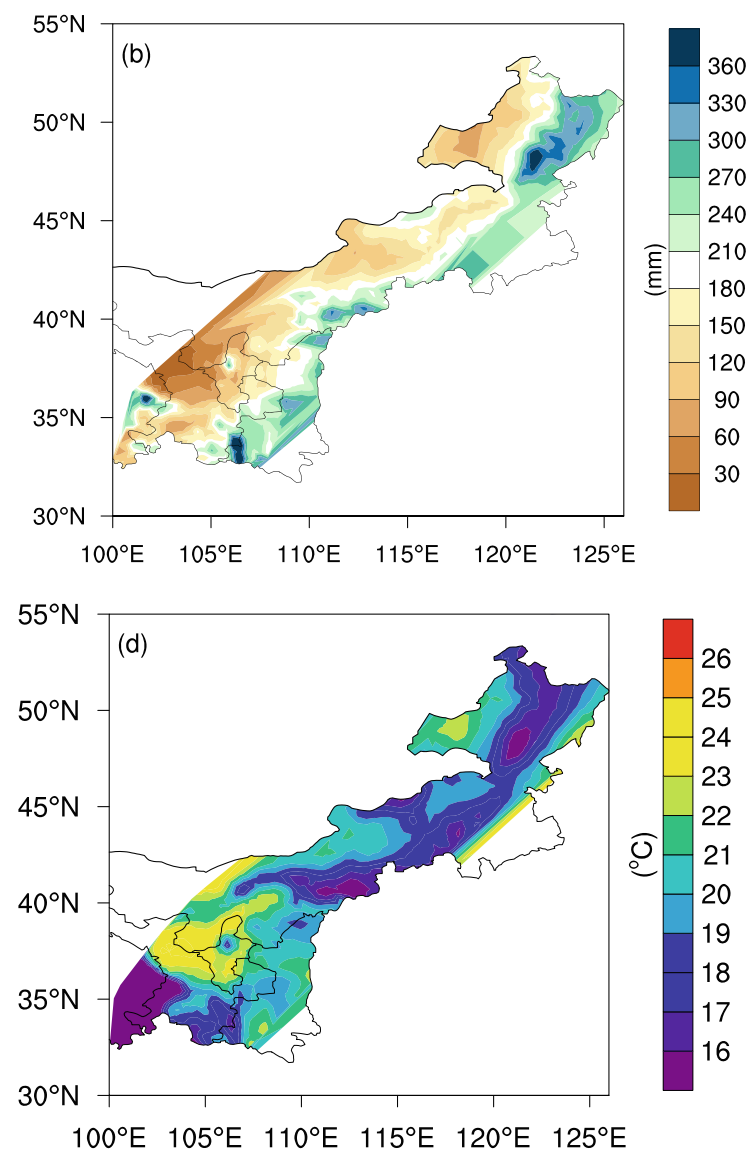

Fig. 2 Average summer precipitation and temperature from 1988 to 2017 (June through August). a Actual precipitation, b simulated precipitation, c actual temperature, and $\mathbf{d}$ simulated temperature 
Table 1 Vegetation types in Bats1e

\begin{tabular}{llll}
\hline Class & Type & Class & Type \\
\hline 1 & Crop/mixed farming & 12 & Ice cap/glacier \\
2 & Short grass & 13 & Bog or marsh \\
3 & Evergreen needleleaf tree & 14 & Internal Water \\
4 & Deciduous needleleaf tree & 15 & Ocean \\
5 & Deciduous broadleaf tree & 16 & Evergreen shrub \\
6 & Evergreen broadleaf tree & 17 & Deciduous shrub \\
7 & Tall grass & 18 & Mixed Woodland \\
8 & Desert & 19 & Forest/Field mosaic \\
9 & Tundra & 20 & Water and land mixture \\
10 & Irrigated Crop & 21 & Urban \\
11 & Semi-desert & 22 & Suburban \\
\hline
\end{tabular}

However, there is a variety of vegetation in China's semiarid regions, e.g., short grasses, deserts, and woodlands. Because the vegetation varies greatly in terms of land surface properties such as thermal capacity, roughness and albedo, it has various influences on regional climate change. The continuous aridification in China's semiarid regions has also caused environmental degradation and water shortages, which have severely restricted regional sustainable development, causing those regions to be severely impacted by climate change (Fu et al. 2005). Although precipitation in the region has increased in the past 20 years, it has not changed the trend of substantial drying. This continuous aridification will further increase land desertification, intensify water shortages, and degrade the ecosystem. Because land surface characteristic parameters vary substantially (Cook et al. 2014; Liu et al. 2014; $\mathrm{Xu}$ and $\mathrm{Xu}$ 2012; Wen et al. 2013), aridification has been further exacerbated, turning the region into an important source of sand and dust aerosols. These negatively affect both the area and other regions, and even the global climate to some degree (Chen et al. 2017; Wang et al. 2017). Therefore, the present study will help improve understanding of the impact of land surface aridification in the East Asian summer monsoon transition zone on regional climate change, and assist in formulating a reasonable response to reduce losses from aridification.

\section{Material and methods}

\subsection{Materials}

In this study, ERA-Interim reanalysis data with horizontal resolution $0.75^{\circ} \times 0.75^{\circ}(\sim 80 \mathrm{~km})$ and 37 vertical layers served as lateral boundary conditions. ERA-Interim is the latest global atmospheric reanalysis data released by the European Centre for Medium-Range Weather Forecasts (ECMWF). Assimilating satellite brightness temperature,
Table 2 Parametric scheme

\begin{tabular}{ll}
\hline Physical process & Simulation scheme \\
\hline Cumulus convection parameterization & MIT-Emanuel \\
Large-scale precipitation program & SUBEX \\
PBL scheme & Holtslag \\
Radiation transmission scheme & NCAR CCM3 \\
Sea surface flux scheme & Zeng \\
Barometric gradient scheme & Hydrostatic recursion scheme \\
\hline
\end{tabular}

atmospheric motion state inverted by scatterometer and satellite, and ozone and conventionally observed data inverted by GPS occultation and satellite using the advanced 4D-Var variational assimilation system Cy31r2, ERA-Interim reanalysis data are currently recognized as the highest-quality reanalysis data in the world.

The live data used herein were collected on a daily basis by the China Surface International Exchange Station and compiled by the China Meteorological Administration. This dataset contains daily data of meteorological elements collected by China's reference and basic meteorological stations since January 1951. Here, we used daily precipitation data observed over the past 30 years, i.e., from 1 January 1988 to 31 December 2017.

\subsection{Study area}

Based on Zhang's (2017c) division of semiarid regions in China, the shaded area in Fig. 1 was taken as the study area. As a unique land type and ecological environment area in the marginal area affected by the East Asian summer monsoon transition zone, the study area extends from southwest to northeast across a long belt of mainland China, with a total area of nearly 150 million $\mathrm{km}^{2}$. With sparse surface vegetation, this area has a relatively weak ability to resist erosion and conserve water. Owing to the unique climatic environment and geomorphology, land types in the area are dominated by farming-pastoral ecotones or ecological transition areas. With a fragile ecological environment, severe soil erosion, and substantial spatiotemporal variation of land surface characteristics such as vegetation state, soil moisture, and physical and chemical soil properties, the area is a typical region sensitive to climate change (Zhang et al. 2017b). There are 12 land-use types in the area, mainly short grass (54.7\%), desert and semidesert (20\%), and a small amount of forest (Fig. 2).

\subsection{Models and protocol}

Bats1e, the latest version of the biosphere atmosphere transfer scheme (Bats), is the land surface model used in our study. Designed by Dickinson et al. (1986), through continuous improvement and optimization, this model has been extensively 

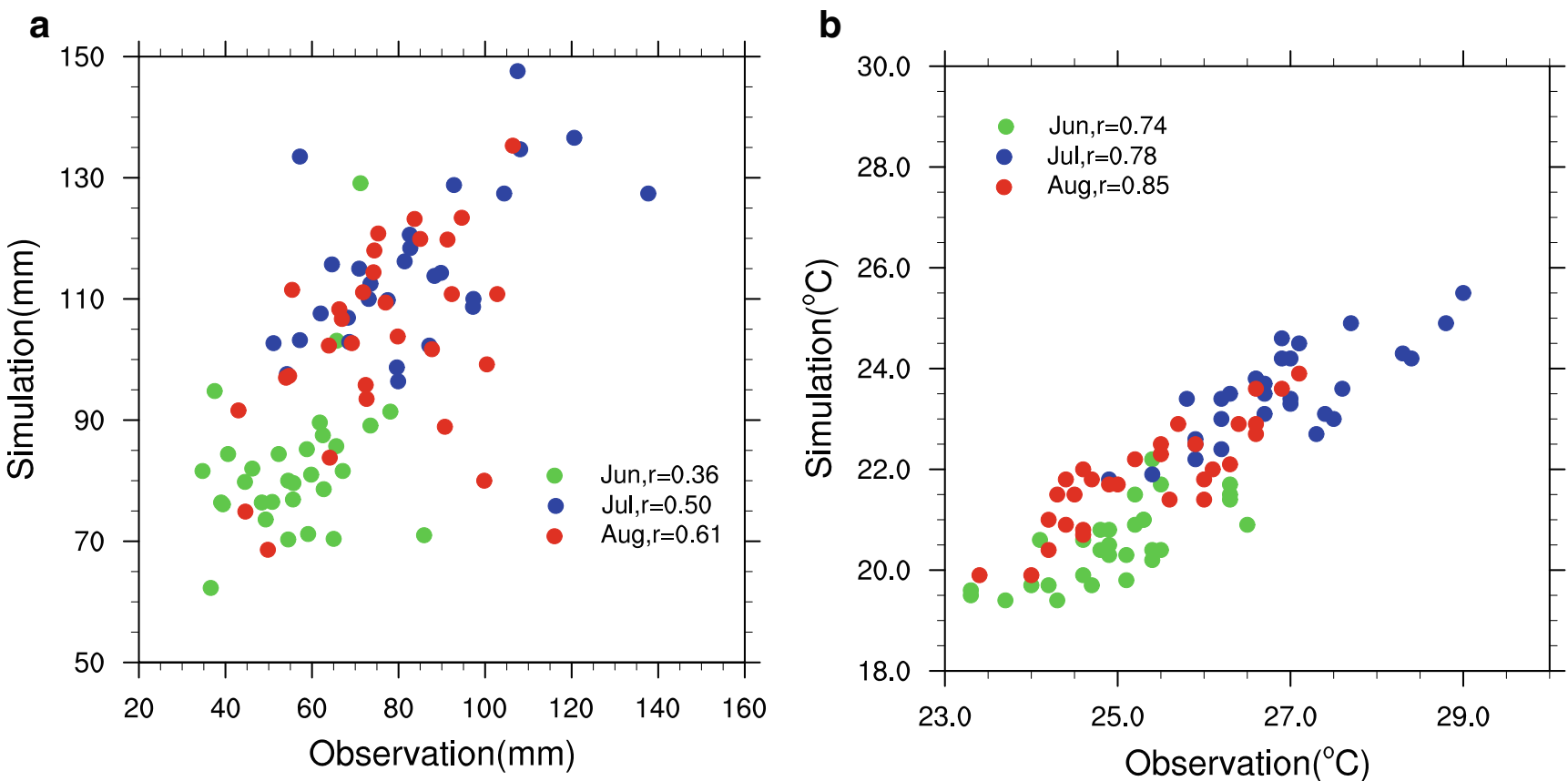

Fig. 3 Correlative maps of actual and simulated regional average summer precipitation and temperature from 1988 to 2017 (June through August). a Precipitation and $\mathbf{b}$ temperature

applied in practice. As a typical single-layer, large-leaf model, Bats is a parametric scheme treating the exchange of radiation, moisture, heat, and momentum over vegetation-covered surfaces and soil hydrothermal processes. It was established based on relevant physical concepts and theories according to a series of directly observed land surface parameters, which objectively consider the role of vegetation in the terrestrial hydrothermal process. It consists of a layer of vegetation, of snow cover, and three layers of soil, and includes physical processes such as precipitation, snowfall, evapotranspiration, runoff, infiltration, and snowmelt. The model comprehensively considers the effects of vegetation and the ground surface on the exchange of momentum, energy, and water vapor between the atmosphere and land surface (Dickinson et al. 1986, 1993). Bats1e contains 22 types of surface vegetation (Table 1). Subgrid-scale changes for terrain and land types were calculated using the mosaic method.

We also used the latest version of the regional climate model RegCM4.6 (Dickinson et al. 1989; Giorgi and Bates 1989; Giorgi et al. 1993a), coupled with Basts1e. A large number of simulation experiments show that the coupled regional climate model system has good simulation performance for China's regional climate change, so it has been widely used in scientific research and climate prediction.

Vegetation degradation, intensified desertification, and considerable changes in land surface characteristic parameters are the most direct manifestations of LSA. Hence, two simulation experiments were designed for the present study:
Experiment I: The original underlying surface was maintained

Experiment II: Vegetation in the study area was changed to desert

In the experiments, the test center was at $37.39^{\circ} \mathrm{N}$ and $103.48^{\circ} \mathrm{E}$, with a horizontal grid spacing of $30 \mathrm{~km}$. The number of grid points in the east-west and north-south horizontal directions was $145 \times 160$. We used the Arakawa-Lamb B staggered grid and Lambert projection as the flat projection. The vertical resolution was non-uniform and had 23 layers. With a mixed coordinate system applied, the top pressure was $50 \mathrm{hPa}$. Reanalysis data released by the ECMWF (ERA-Interim) with horizontal resolution $0.75^{\circ} \times 0.75^{\circ}$ and 37 vertical layers served as the lateral boundary. NOAA's Optimum Interpolation Sea Surface Temperature average monthly data were used for sea surface temperature. The simulation period was 1 January 1987 to 31 December 2017, in which 1987 was the model spin-up period and the later 30 years (1988-2017) the analysis period. Table 2 shows the physical schemes of the model.

\section{Results and discussion}

\subsection{Evaluation of control test}

Figure 2 shows actual average summer precipitation in the study area and that simulated by RegCM4.6. From the actual analysis (Fig. 2a), the precipitation is $<360 \mathrm{~mm}$, gradually increasing from northwest to southeast. The area with the least 

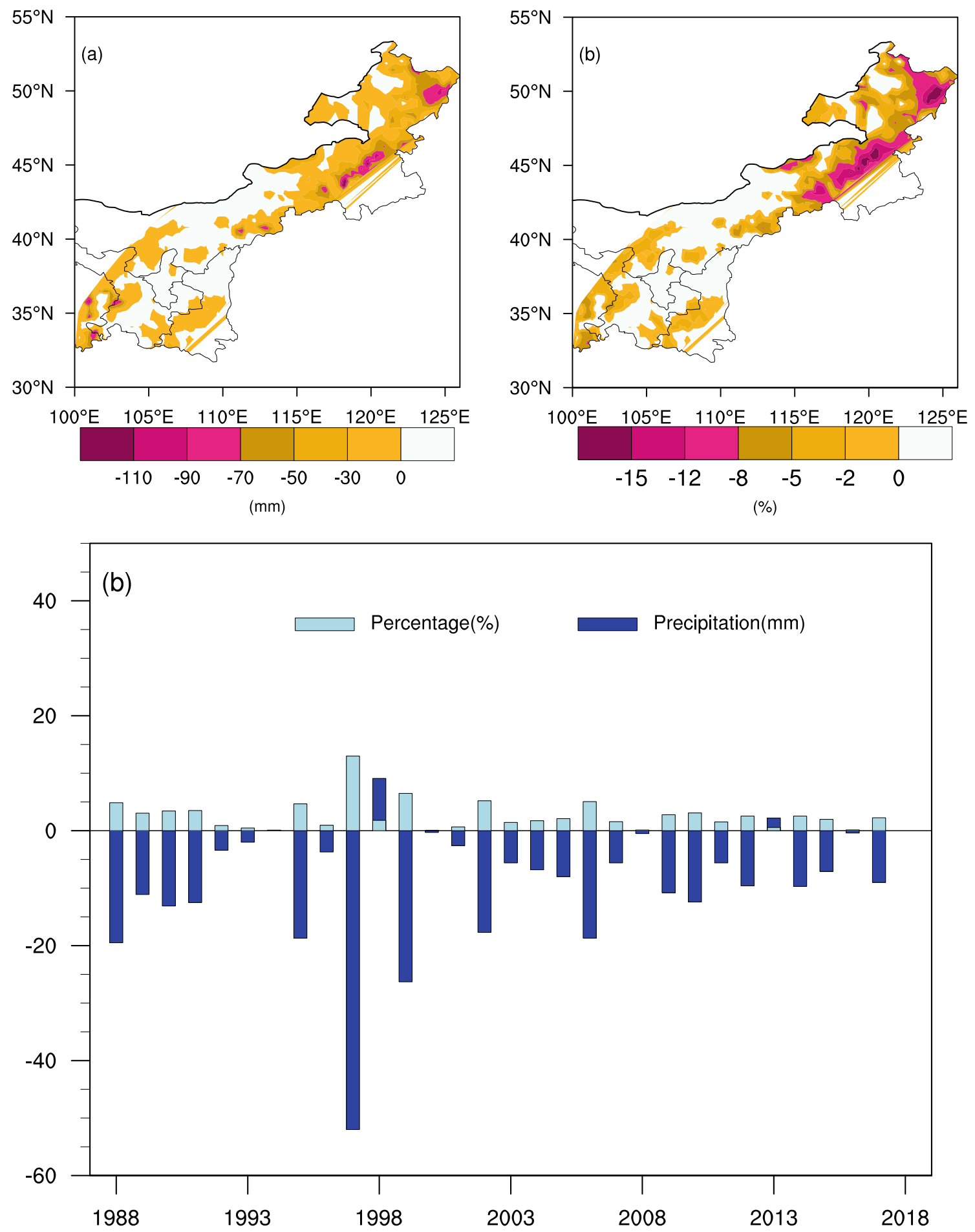

Fig. 4 Variation of summer precipitation after aridification. a Change in precipitation, b percentage change in precipitation, and $\mathbf{c}$ regional average precipitation anomaly

precipitation, $<100 \mathrm{~mm}$, is in the desert area of Inner Mongolia. The area with the most precipitation, $360 \mathrm{~mm}$, is in the eastern part of the northwestern region and eastern Inner Mongolia, at the west and east edges of the study area, respectively. Precipitation in certain areas exceeds $360 \mathrm{~mm}$. From the simulated rainfall analysis (Fig. 2b), except for the eastern part of the northwest region and eastern Inner Mongolia where the precipitation in certain areas is slightly larger than actual, the spatial distribution of the simulated precipitation is very consistent with the actual. Average summer temperature in the study area is high in the middle and low on both east and west sides. Maximum temperature in the Tengger Desert is $>20$ 

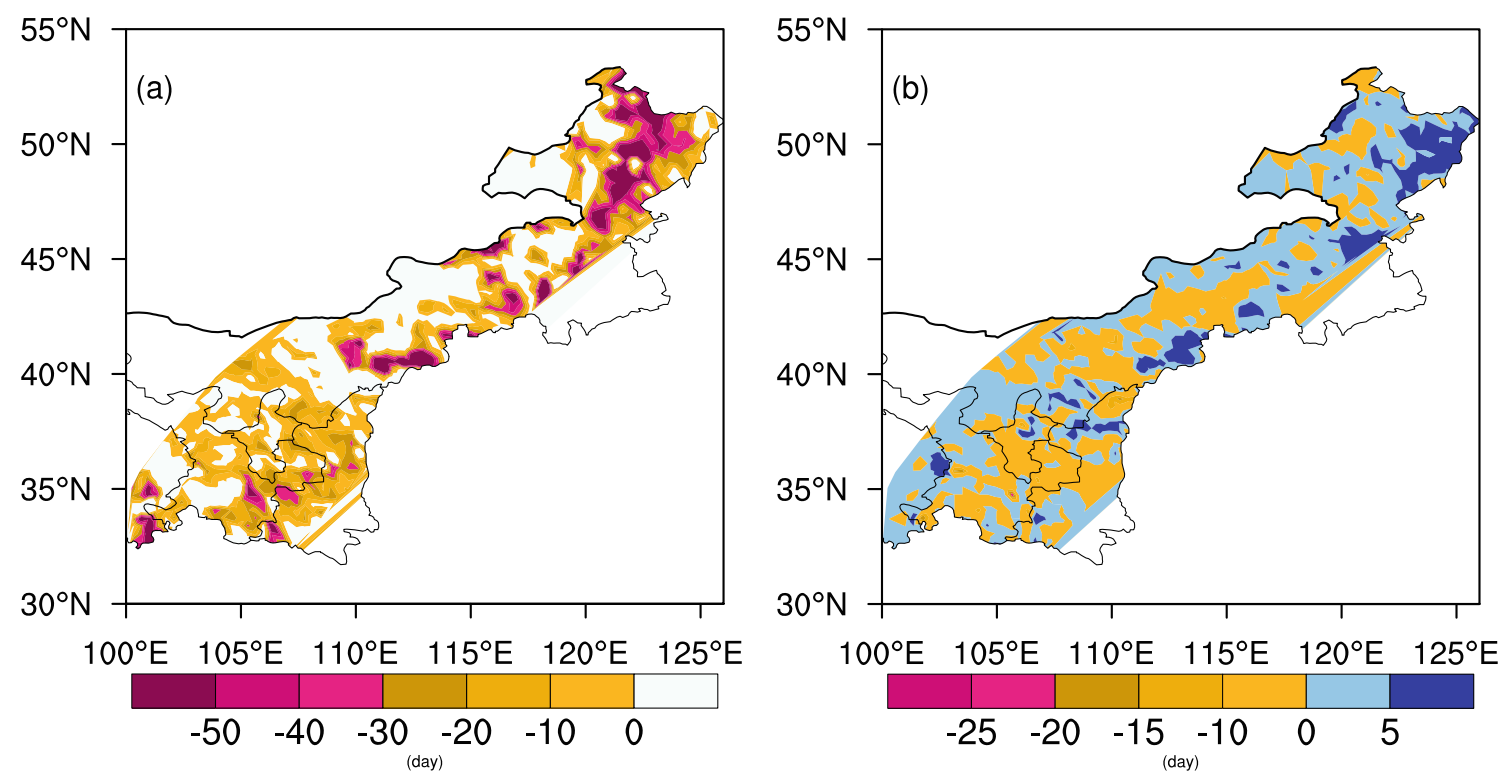

(c)

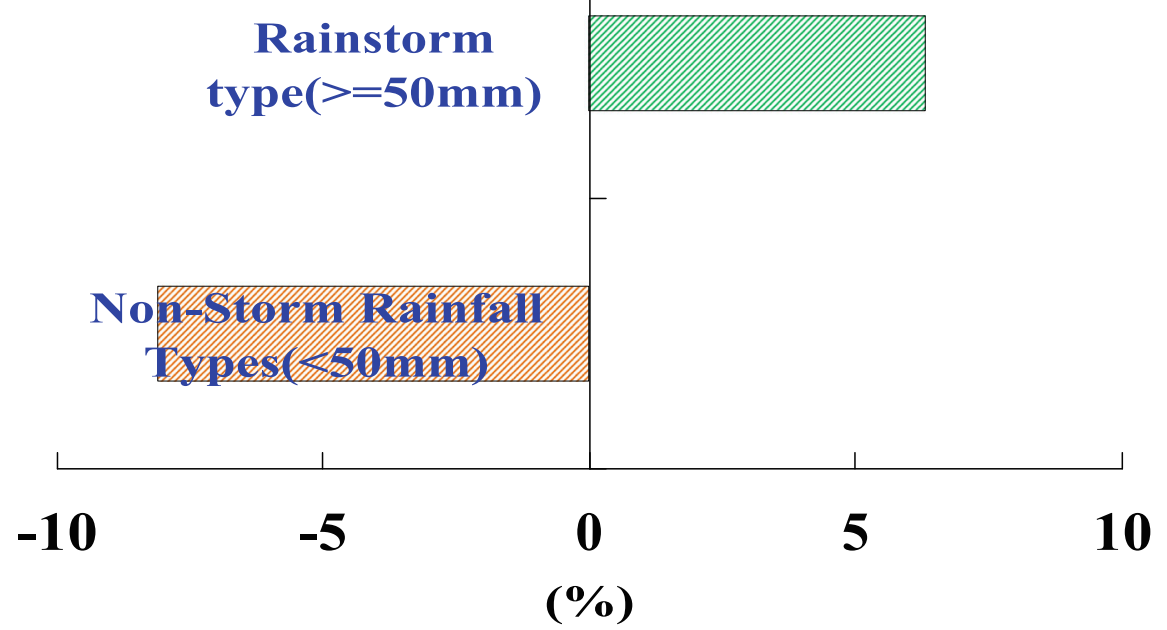

Fig. 5 Variation of frequency of precipitation at different magnitudes. a Below the magnitude of rainstorm, $\mathbf{b}$ at the magnitude of rainstorm, and $\mathbf{c}$ regional average of percentage change in precipitation at different magnitudes

${ }^{\circ} \mathrm{C}$, and the average temperature at the western and eastern peripheries of the study area is $16{ }^{\circ} \mathrm{C}$. The spatial distribution of average temperature simulated by the model agrees with actual data, except for the simulated temperature in western Mongolia, which is $1-2{ }^{\circ} \mathrm{C}$ cooler than actual.

From the analysis of simulated summer regional average precipitation and temperature, it is evident that the model has a strong ability to reproduce precipitation and temperature changes across the study area. There is a strong linear relationship between actual data and the simulated precipitation and temperature curves (Fig. 3a, b). Monthly precipitation correlation coefficients from June through August are 0.36, 0.50, and 0.61, respectively, reaching significance levels $\alpha<0.05,0.005$, and 0.001 (critical correlation coefficients reaching $\alpha<0.05,0.005$, and 0.001 over the past 30 years are $0.355,0.49$, and 0.56 , respectively). The correlation coefficients of temperature are $0.74,0.78$, and 0.85 , all of which reach significance level $\alpha<0.001$. The simulated regional average precipitation is only $\sim 30 \mathrm{~mm}$ greater than the actual value, and the temperature is only $1{ }^{\circ} \mathrm{C}$ lower than the actual value.

\subsection{Influence of LSA on precipitation}

From analysis of the difference between simulated precipitation in the sensitivity test and that in the control test (Fig. 4a) and corresponding percentages (Fig. 4b), it is seen that LSA in the study area led to an average reduction of $0-30 \mathrm{~mm}$ in summer precipitation. The greatest reduction in precipitation was in eastern Inner Mongolia. Here, most areas had a reduction of $>50 \mathrm{~mm}$, and some areas $90-110 \mathrm{~mm}$, which is $\sim 5 \%$ 

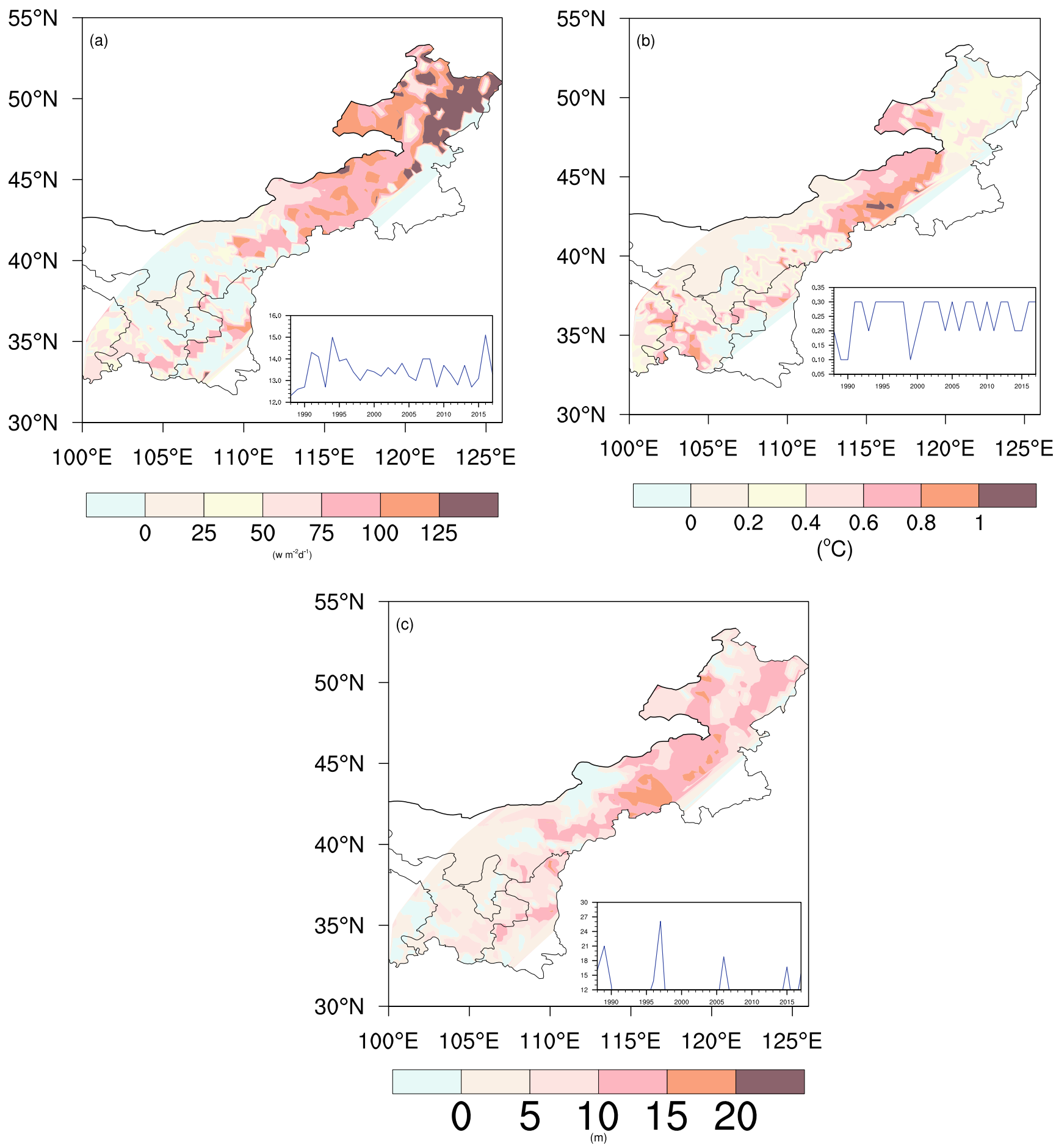

Fig. 6 Variation of sensible heat, land surface temperature, and height of boundary layer

of annual average precipitation. That figure in some areas reached as much as $15-20 \%$. Vegetation in this region used to be short grasses, mixed forests, and forests, indicating that LSA had an important influence on precipitation in the region. South Gansu also had reduced precipitation. Annual precipitation generally decreased by $30-50 \mathrm{~mm}$ (or $\sim 5 \%$ of annual average precipitation), with the reduction in some areas reaching $>70 \mathrm{~mm}(\sim 8 \%$ of the annual average $)$. Precipitation in the central study area increased, and this area was defined as a semi-desert, indicating that circulation change rather than vegetation change was the primary effect on this area. The above analysis shows that in contrast with other arid and semiarid regions, precipitation in the area is simultaneously influenced by atmospheric circulation, 
Fig. 7 Mechanism of influence of land surface aridification on precipitation change

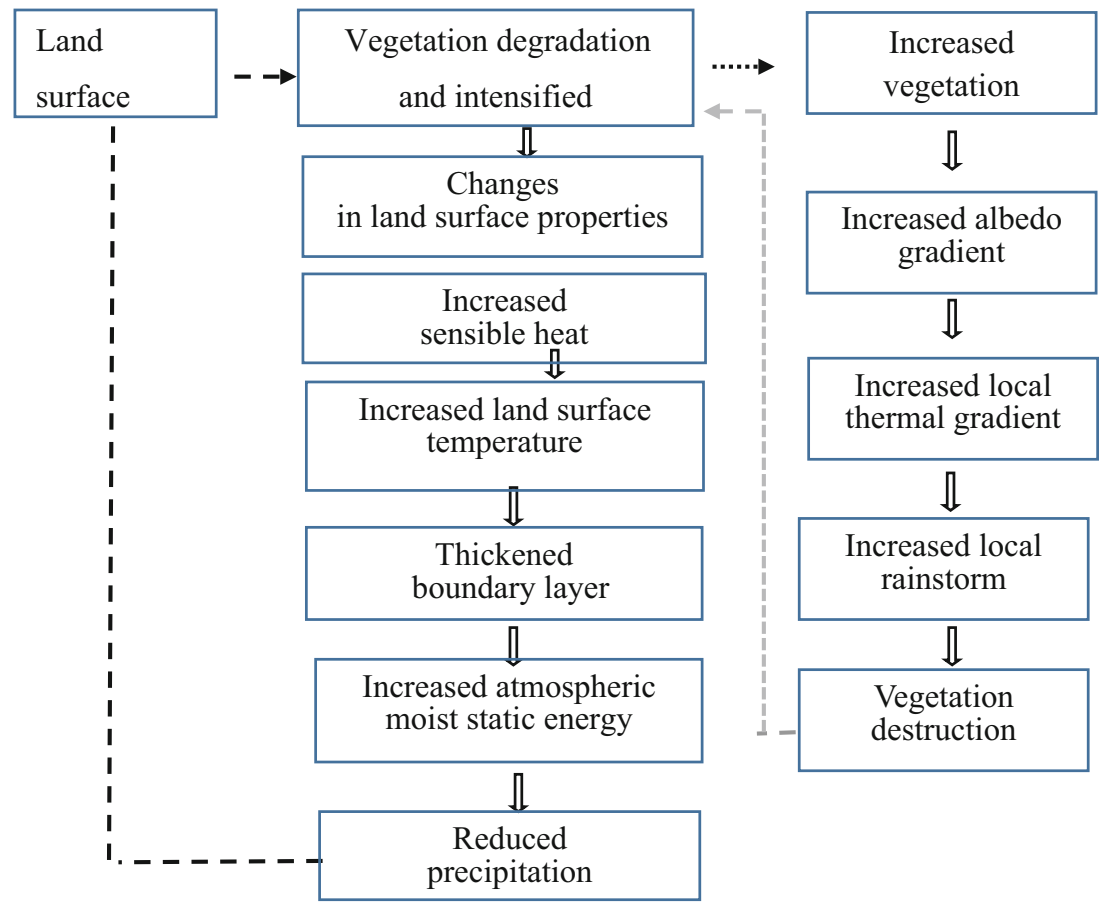

vegetation change, and terrain of the Qinghai-Tibet Plateau, and the influence mechanism is relatively complicated. Analysis of the annual variation of regional average precipitation (Fig. 4c) implies that LSA can reduce summer precipitation in the area by $13.9 \mathrm{~mm}$, or $\sim 2.5 \%$ of average summer precipitation.

Figure 5 shows that aridification also greatly affected the nature of precipitation in the area. Aridification caused a reduction of $\sim 10$ days of precipitation below the magnitude of rainstorm. The western study area had a reduction of 10-20 days ( $\sim 10.8-21.7 \%$ of the total number of days), and some parts had a reduction of 30 days $(\sim 32.6 \%$ of the total number of days). The reduction of precipitation days was the most obvious. The average reduction of these was 30 days $(\sim$ $32.6 \%$ of the total number of precipitation days), and the reduction in some regions reached 50 days $(\sim 54.3 \%$ of that total number). However, across more than half the study area, the number of days with rainstorms increased by $\sim 5$ days. The increase was even more obvious in the western and northeast parts of the study area, reaching $>5$ days $(\sim 5.4 \%$ of the total number of days). From analysis of the average variation probability of precipitation at and below rainstorm magnitude in the study area, the occurrence probability of precipitation below that magnitude decreased by $\sim 13 \%$, while the occurrence probability of rainstorms increased by $\sim 6 \%$. The above analysis shows that LSA has a profound influence on the nature of precipitation in the study area, which is mainly reflected by a decrease in weather system-related precipitation and increase in convective precipitation.

\section{Discussion}

There is always an exchange of energy between the land surface and atmosphere. Surface sensible and latent heats are the main ways for the land surface to transmit energy to the atmosphere. By analyzing differences between average daily sensible heat fluxes obtained in Experiments $\Pi$ and I (Fig. 6a), we found that LSA strengthened the sensible heat flux in most regions, most notably in Northeast China and eastern Inner Mongolia, where the increase exceeded $75 \mathrm{~W}$ $\mathrm{m}^{-\mathrm{w}}$ day ${ }^{-\mathrm{y}}$. The sensible heat flux increased by $>45 \mathrm{~W} \mathrm{~m}^{-5}$ day $^{-y}$ in the northwestern study area. The curve of annual change of sensible heat flux is shown in Fig. 6a, indicating that aridification increased the regional sensible heat flux by $>12.5 \mathrm{~W} \mathrm{~m}^{-2}$ day $^{-\mathrm{y}}$, with drastic change in the $1990 \mathrm{~s}$. The flux in central Mongolia was reduced. The original vegetation in that area was mainly semi-desert, whose thermal capacity is similar to that of desert. Albedo is the factor affecting the change of sensible heat flux. As albedo increased, net radiation declined, and the land surface temperature cooled, thereby reducing the sensible heat flux. Correspondingly, land surface temperature increased (Fig. 6b). That temperature rose by $0.6-0.8^{\circ} \mathrm{C}$ in most areas of the western study area and central Mongolia, with the increase between 0.8 and $1.0^{\circ} \mathrm{C}$ in some areas. As the sensible heat flux and surface temperature rose, the boundary layer height increased (Fig. 6c). Boundary layer thickness in the eastern study area increased the most, at $10-15 \mathrm{~m}$ in most areas and $>75 \mathrm{~m}$ in some. 
Based on the above analyses, land surface aridification in the East Asian summer monsoon transition zone generally reduced regional precipitation. As shown in Fig. 7, because of that aridification, surface thermal capacity decreased and land surface temperature rose, which increased sensible heat transport. As a consequence, the boundary layer thickened, which increased atmospheric moist static energy and reduced precipitation efficiency and weather system-related precipitation, further developing land surface aridification. However, after the land surface became arid, surface properties were altered and the surface vegetation landscape gradient increased. This led to an increased surface albedo gradient, uneven heat transfer on the ground, and increased local gradients of the surface landscape, which raised the probability of heavy convective precipitation.

\section{Conclusions}

In the present study, sensitivity numerical experiments for vegetation degradation over a long period were carried out to explore the influence of LSA in the East Asian summer monsoon transition zone on summer precipitation there. The results show that LSA reduced total regional precipitation, with the greatest changes found in the eastern and western portions of the study area. Moreover, LSA greatly altered the nature of precipitation in the area, which was mainly reflected by an increase in the frequency of precipitation at rainstorm magnitude but a decrease in weather system-related precipitation. It was found that LSA reduced surface thermal capacity, and an increase in sensible heat transferred from the land surface to atmosphere thickened the boundary layer and enhanced atmospheric moist static energy. This reduced weather systemrelated precipitation and further aggravated LSA. In addition, LSA resulted in an enhanced surface vegetation landscape gradient, increased surface albedo gradient, and uneven heat transfer on the ground. It also strengthened local gradients of near-surface temperature, which increased the probability of heavy convective precipitation.

Although we performed simulations to explore the effects of LSA on monsoon precipitation based on integrated results obtained over a long period, actual LSA is a dynamic process of interaction between land surface vegetation and the atmosphere. However, limited by immature theories and technologies to determine dynamic vegetation change using the current surface model, there has been no study of the influence of dynamically changing LSA on monsoon precipitation. Therefore, a new generation of land surface models is needed to further examine the influence of LSA on monsoon precipitation in the summer monsoon transition zone of China and the complex interaction between them.

Supplementary Information The online version contains supplementary material available at https://doi.org/10.1007/s00704-021-03523-1.

Acknowledgments The authors acknowledge the ECMWF for providing the reanalysis data and The International Centre for Theoretical Physics (ICTP) for providing the Regional Climate model (RegCM). We appreciate the anonymous reviewers for their insightful and constructive comments, which lead to significant improvements of the manuscript.

Author contributions Writing - review and editing, Ren Y.L.; providing initial idea, Yue P. and Zhang Q.; funding acquisition, Wang X.P.; typesetting, Liu X.Y.

Funding This study is supported by the NSFC key program (41630426), the Natural Science Foundation of Gansu Province (20JR5RA119) and The Innovation Team of Gansu Meteorological Bureau (GXQXCXTD2020-02).

\section{Compliance with ethical standards}

Conflict of interest The authors declare that they have no conflict of interest.

Open Access This article is licensed under a Creative Commons Attribution 4.0 International License, which permits use, sharing, adaptation, distribution and reproduction in any medium or format, as long as you give appropriate credit to the original author(s) and the source, provide a link to the Creative Commons licence, and indicate if changes were made. The images or other third party material in this article are included in the article's Creative Commons licence, unless indicated otherwise in a credit line to the material. If material is not included in the article's Creative Commons licence and your intended use is not permitted by statutory regulation or exceeds the permitted use, you will need to obtain permission directly from the copyright holder. To view a copy of this licence, visit http://creativecommons.org/licenses/by/4.0/.

\section{References}

Cao FQ, Dan L, Ma ZG (2015) Simulative study of the impact of the cropland change on the regional climate over China. Acta Meteorol Sin 73(1):128-141

Chen H, Sun J (2015) Changes in drought characteristics over China using the standardized precipitation evapotranspiration index. J Clim 28(13):5430-5447

Chen S, Huang J, Kang L (2017) Emission, transport, and radiative effects of mineral dust from the taklimakan and gobi deserts: comparison of measurements and model results. Atmos Chem Phys 17(3): $1-43$

Cheng SJ, Huang JP (2016) Enhanced soil moisture drying in transitional regions under a warming climate. J Geophys Res Atoms 121:25422555

Cook BI, Smerdon JE, Seager R (2014) Global warming and 21st, century drying. Clim Dyn 43(9-10):2607-2627

Dai AG (2012) Increasing drought under global warming in observations and models. Nat Clim Chang 3:52-58 
Dickinson RE, Kennedy PJ, Henderson-Sellers A (1986) Biosphere atmosphere transfer scheme (bats) for the NCAR community climate model.

Dickinson RE, Kennedy PJ, Giorgi F (1989) A regional climate model for the western United States. Clim Chang 15(3):383-422

Dickinson R, Henderson, A, Kennedy P (1993) Biosphere-atmosphere transfer scheme (BATS) version 1e as coupled to the NCAR Community Climate Model. NCAR Tech. Note.

Ding YH, Si D, Liu YJ (2018) On the characteristics, driving forces and inter-decadal variability of the East Asian summer monsoon. Chinese J Atmos Sci (in Chinese) 42(3):533-558

Donat MG, Lowry AL, Alexander LV (2017) Addendum: more extreme precipitation in the world's dry and wet regions. Nat Clim Chang 7(2):154-158

Feng S, Fu Q (2013) Expansion of global drylands under a warming climate. Atmos Chem Phys 13(6):10081-10094

Fu CB, Guo ZS, Wang D (2005) Evolution of life-supporting environment in our nation and the predictive study of aridification in northern china: scientific innovations and its contribution to national demands. Adv Earth Science 20(11):1168-1175

Giorgi F, Bates GT (1989) The climatological skill of a regional model over complex terrain. Mon Weather Rev 117(11):23-25

Giorgi F, Marinucci MR, Bates GT (1993a) Development of a secondgeneration regional climate model $(\mathrm{reg} \mathrm{cm} 2)$. part I: boundary-layer and radiative transfer processes. Mon Weather Rev 121(10):2794 2813

Giorgi F, Marinucci MR, Bates GT (1993b) Development of a 2nd generation regional climate model (Regcm 2$)$ : convective processes and assimilation of lateral boundary-conditions. Mon Weather Rev 121(10):2814-2832

Gou JJ, Wang F, Jing K (2018) Cooling effect induced by restoration on the Loess Plateau. Acta Ecol Sin 38(11):3970-3978

Hua WJ, Chen HS (2013) Recognition of climatic effects of land use/land cover change under global warming. Chin Sci Bull 58:3852-3858

Huang JP, Guan X, Ji F (2012) Enhanced cold-season warming in semiarid regions. Atmos Chem Phys 12:5391-5398

Huang JP, Ma X, Xie YK (2015) Global semi-arid climate change over last 60 years. Clim Dyn 46:1131-1150

IPCC (2013) Climate Change 2013: the physical science basis. Contribution of Working Group I to the Fifth Assessment Report of the Intergovernmental Panel on Climate Change. Cambridge University Press, Cambridge and New York, p 1535

Li J, Wang B (2018) Predictability of summer extreme precipitation days over eastern China. Clim Dyn 51:4543-4554

Li JH, Chen HS, Hua WJ (2013) Sensitivity experiments on impacts of large-scale land use change on surface energy balance, hydrological cycle and regional climate over East Asia. Trans Atmos Sci 36(2): 184-191 (in Chinese)

Li CX, Zhao TB, Ma ZG (2014) Impacts of anthropogenic activities on climate change in arid and semiarid areas based on CMIP5 models. Chin Sci Bull (Chin Ver) 59:2972-2988

Liu YH, Feng JM, Ma ZG (2014) An analysis of historical and future temperature fluctuations over China based on CMIP5 simulations. Adv Atmos Sci 31:457-467

Ma ZG, Fu CB (2005) Decadal variations of arid and semi-arid boundary in China. Chinese J Geophys (in Chinese) 48(3):519-525
Ma ZG, Ren XB (2007) Drying trend over China from 1951 to 2006. Adv Clim Chang Res 3(4):195-201

Ma ZG, Fu CB, Yang Q (2018) Drying trend in Northern China and its shift during 1951-2016. Chinese J Atmos Sci (in Chinese) 42(4): 951-961

Mitchell D, James R, Forster PM (2016) Realizing the impacts of a $1.5^{\circ} \mathrm{C}$ warmer world. Nat Clim Chang 6:735-737

Orlowsky B, Seneviratne SI (2012) Elusive drought: uncertainty in observed trends and short- and long-term CMIP5 projections. Hydrol Earth Syst Sci 9:13773-13803

Otterman J (1974) Baring high-albedo soils by overgrazing: a hypothesized desertification mechanism. Science 186(1):531-533

Ou TH, Chen DL, Linderholm HW (2013) Evaluation of global climate models in simulating extreme precipitation in China. Tellus A: Dynamic Meteorol Oceanogr 65:1

Tang X, Qian WH, Liang P (2006) Climatic features of boundary belt for East Asian summer monsoon. Plateau Meteor (in Chinese) 25(3): 375-381

Tiwari A, Fan ZX, Jump AS (2017) Warming induced growth decline of Himalayan birch at its lower range edge in a semi-arid region of Trans-Himalaya, central Nepal. Plant Ecol 218(5):621-633

Wang F, Zhao X, Gerlein-Safdi C (2017) Global sources, emissions, transport and deposition of dust and sand and their effects on the climate and environment: a review. Front Environ Sci Eng 11(1):13

Wei XQ (2016) Study on the sensitivity of the East Asian climate to the underlying surface parameters in the arid and semi arid area.

Wen HQ, Zhang X, Xu Y (2013) Detecting human influence on extreme temperatures in China. Geophys Res Lett 40:1171-1176

$\mathrm{Xu} \mathrm{Y,} \mathrm{Xu} \mathrm{CH} \mathrm{(2012)} \mathrm{Preliminary} \mathrm{assessment} \mathrm{of} \mathrm{simulations} \mathrm{of} \mathrm{climate}$ changes over China by CMIP5 multi-models. Atmos Oceanic Sci Lett 5:489-494

Zhang L, Zhou T (2015) Drought over East Asia: a review. J Clim 28(8): 150203142724009

Zhang Q, Zheng Y, Singh VP (2017a) Summer extreme precipitation in eastern China: mechanisms and impacts. J Geophys Res Atoms 122(5):2766-2778

Zhang Q, Kong D, Singh VP (2017b) Response of vegetation to different time-scales drought across China: spatiotemporal patterns, causes and implications. Glob Planet Chang 152:1-11

Zhang Q, Zhang HL, Zhang L (2017c) Study on summer monsoon transition zone and its land-air interaction. Adv Earth Science 32(10): 1009-1019

Zhao JC, Liu SH (2015) Research on the impact of vegetation change on land-atmosphere coupling strength in northwest China, Chinese J Geophys. (in Chinese). 58(1):47-62

Zhao TB, Chen L, Ma ZG (2014) Simulation of historical and projected climate change in arid and semiarid areas by CMIP5 models. Chin Sci Bull 59:412-429

Zhao SM, Zuo HC, Wei XQ (2018) Numerical simulation of climate effect in East Asia by plastic film mulching farmland in arid area. Arid Zone Res 35(6):1363-1372

Publisher's note Springer Nature remains neutral with regard to jurisdictional claims in published maps and institutional affiliations. 